ISSN 1996-1944

www.mdpi.com/journal/materials

Article

\title{
Silicate Removal in Aluminum Hydroxide Co-Precipitation Process
}

Chiharu Tokoro $^{1 *}$, Shinya Suzuki ${ }^{2}$, Daisuke Haraguchi ${ }^{2}$ and Sayaka Izawa ${ }^{2}$

1 Faculty of Science and Engineering, Waseda University, 3-4-1 Okubo, Shinjuku-ku, Tokyo 169-8555, Japan

2 Graduate School of Creative Science and Engineering, Waseda University, 3-4-1 Okubo, Shinjuku-ku, Tokyo 169-8555, Japan; E-Mails: shinya.suzuki55@ gmail.com (S.S.); d.haraguchi@aoni.waseda.jp (D.H.); izasaya@ ruri.waseda.jp (S.I.)

* Author to whom correspondence should be addressed; E-Mail: tokoro@ waseda.jp; Tel./Fax: +81-3-5286-3320.

Received: 3 December 2013; in revised form: 2 January 2014 / Accepted: 5 February 2014 / Published: 11 February 2014

\begin{abstract}
The removal mechanisms of silicate using an aluminum hydroxide co-precipitation process was investigated and compared with an adsorption process, in order to establish an effective and validated method for silicate removal from wastewater. Adsorption isotherms, XRD and FT-IR analyses showed that silicate uptake occurred by adsorption to boehmite for initial $\mathrm{Si} / \mathrm{Al}$ molar ratios smaller than two, but by precipitation of poorly crystalline kaolinite for the ratios larger than two, in both co-precipitation and adsorption processes. Silicate was removed by two steps: (i) an initial rapid uptake in a few seconds; and (ii) a slow uptake over several hours in both processes. The uptake rate in the first step was higher in the co-precipitation process than in adsorption process, presumably due to increased silicate adsorption to boehmite and rapid precipitation of kaolinite. These results suggest that silicate removal using aluminum salts could be effectively achieved if the $\mathrm{pH}$ adjustment and aluminum concentration are strictly controlled.
\end{abstract}

Keywords: co-precipitation; adsorption; aluminum hydroxide; boehmite; kaolinite; sorption density 


\section{Introduction}

Silica is the second most abundant element, comprising $27.7 \%$ of the earth's crust. Its content in natural water is generally between 20 and $60 \mathrm{mg} \cdot \mathrm{dm}^{-3}$, but can be as high as $100 \mathrm{mg} \cdot \mathrm{dm}^{-3}$ in specific natural waters [1]. Although the solution chemistry of silica has been extensively studied, its polymerization or colloidalization in water requires further investigation to understand the mechanism of silica removal from water.

Silica scale, an intermediate product of mono-silicic acid that polymerizes to colloidal silica, clogs water pipes and decreases thermal efficiencies of boilers. Silicate in solution should therefore be removed to a final concentration of less than $10 \mathrm{mg} \cdot \mathrm{dm}^{-3}$. In particular, a decrease in processing efficiency of reverse osmosis (RO) membranes by silica scale is problematic.

RO membrane technology is increasingly being used in chemical engineering separation. For example, after the Great East Japan Earthquake, it was proposed that RO purification could be employed for water extraction from incinerators which hold large quantities of water. This extracted water could be used for both drinking and general use in case of emergency. Silica fouling has been the major unresolved problem in the RO purification process [2,3]. It occurs when dissolved silica exceeds the solubility limit and precipitates on its own or with other compounds. Therefore, prior to using RO membranes for water containing large concentrations of silicate ions, it is necessary to remove the dissolved silica [4,5].

The most common method for removing silicate ions from water is a lime softening process by the addition of slaked lime (calcium hydroxide) [6]. Sodium hydroxide has also been used as an agent for silicate ion removal by precipitation [4]. Other silicate ion removal methods include adsorption or co-precipitation treatments using aluminum or iron salts [5]. Although silicate wastewater treatment using these methods is widely applied, removal mechanisms are unknown.

We investigate the removal mechanisms of silicate co-precipitation with aluminum hydroxide in aqueous systems, in order to establish an effective method of silicate removal from wastewater. Synthetic wastewater containing silicate and aluminum ions was prepared at approximately $\mathrm{pH} 12$, and the $\mathrm{pH}$ was then rapidly decreased to $\mathrm{pH}$ 9. Because co-precipitation reactions are influenced by solution conditions such as $\mathrm{pH}$ and ionic strength, these factors were precisely controlled. Previously, we confirmed that comparison between co-precipitation and simple adsorption was useful for elucidating the removal mechanism for $\mathrm{As}(\mathrm{V})$ co-precipitation with ferrihydrite/aluminum hydroxide and F(-I) co-precipitation with aluminum hydroxide [7-11]. Therefore, in this study simple adsorption experiments in which silicate ions were adsorbed to aluminum hydroxide were conducted and compared with co-precipitation experiments. Sorption isotherms were generated and analyzed to identify the mechanism of silicate uptake. The residue was evaluated using X-ray diffraction (XRD) and Fourier transform infrared spectroscopy (FT-IR) to investigate the mineralogical form of precipitates and sorption form of silicate in precipitates. Through detailed mechanism elucidation of silicate removal by aluminum salts, we proposed how $\mathrm{pH}$ and aluminum ion concentrations should be controlled in order to establish an effective silicate removal method. 


\section{Materials and Methods}

\subsection{Standards and Reagents}

All chemicals and solutions used in this study were of analytical grade and were purchased from Kanto Chemicals Inc., Tokyo, Japan. The silicate and aluminum solutions were prepared from $\mathrm{Na}_{2} \mathrm{SiO}_{3} \cdot 9 \mathrm{H}_{2} \mathrm{O}$ and $\mathrm{Al}\left(\mathrm{NO}_{3}\right)_{3} \cdot 9 \mathrm{H}_{2} \mathrm{O}$, respectively. For all experiments, the $\mathrm{pH}$ and ionic strength were adjusted by the addition of $0.05 \mathrm{M} \mathrm{HNO}_{3}, \mathrm{KOH}$ and $\mathrm{KNO}_{3}$. Specifically, the $\mathrm{pH}$ was fixed at 9 and the ionic strength was fixed at 0.05 . All experiments were conducted at $25{ }^{\circ} \mathrm{C}$ at least in triplicate and the error was confirmed to be within $1 \%$.

\subsection{Co-Precipitation Experiment}

Co-precipitation experiments involved the formation of aluminum hydroxide in the presence of silicate ions. $\mathrm{Al}\left(\mathrm{NO}_{3}\right)_{3} \cdot 9 \mathrm{H}_{2} \mathrm{O}$ and silicate solutions were initially combined at above $\mathrm{pH} 12$ in $0.5 \mathrm{dm}^{3}$ of ion-exchanged and deionized (DI) water to maintain both silicate and aluminum as ions. The $\mathrm{pH}$ and ionic strength were then adjusted to 9 and 0.05 , respectively. The initial silicate concentration was fixed at $0.71 \mathrm{mmol} \cdot \mathrm{dm}^{-3}\left(20 \mathrm{mg} \cdot \mathrm{dm}^{-3}\right)$ or $1.78 \mathrm{mmol} \cdot \mathrm{dm}^{-3}\left(50 \mathrm{mg} \cdot \mathrm{dm}^{-3}\right)$ and the aluminum concentration was varied to adjust the initial $\mathrm{Si} / \mathrm{Al}$ molar ratio from 0.125 to 10 .

The suspension was then agitated using a magnetic stirrer while controlling the $\mathrm{pH}$ (accomplished by adding a few drops of $\mathrm{KOH}$ ) for $1 \mathrm{~h}$. With the exception of the time variation experiments, the reaction time was fixed at $1 \mathrm{~h}$. The suspension was then filtered through a $0.1 \mu \mathrm{m}$ membrane filter. The filtrates were analyzed by Inductively Coupled Plasma Atomic Emission Spectroscopy: ICP-AES (Seiko Instruments Inc., SPS-7800, Chiba, Japan) to measure the residual concentration of Si and Al.

\subsection{Adsorption Experiment}

The adsorption experiments were conducted using the same conditions as the co-precipitation experiments. The aluminum hydroxide suspensions and silicate solutions were prepared separately in $0.5 \mathrm{dm}^{3}$ of deionized and distilled water to obtain twice the target concentration of silicate and aluminum. The $\mathrm{pH}$ and ionic strength were adjusted to target levels in both solutions, which were then combined and agitated for $1 \mathrm{~h}$. The $\mathrm{pH}$ was adjusted to 9 by the addition of a KOH. After agitation, the suspension was filtered through a $0.1-\mu \mathrm{m}$ membrane filter, and the filtrate analyzed by ICP-AES to measure the concentration of $\mathrm{Si}$ and $\mathrm{Al}$, as well as co-precipitation.

\subsection{X-Ray Diffraction (XRD) Analysis}

The filter residues of co-precipitation and simple adsorption were analyzed by XRD (RIGAKU, Inc. RINT Ultima III, Tokyo, Japan). For XRD analysis, the initial Al concentration was adjusted to $40 \mathrm{mg} \cdot \mathrm{dm}^{-3}$ and the initial Si concentration was varied according to the Si/Al molar ratio. The filter residues from the co-precipitation and adsorption experiments were freeze-dried at $-45{ }^{\circ} \mathrm{C}$ and $10 \mathrm{~Pa}$ for at least $24 \mathrm{~h}$ to avoid crystallization or mineralogical transformation.

Powder XRD patterns were obtained using a copper target $(\mathrm{Cu} K \alpha)$, a crystal graphite monochromator and a scintillation detector. The X-ray source was operated at $40 \mathrm{kV}$ and $30 \mathrm{~mA}$ by 
step-scanning from $2^{\circ}$ to $80^{\circ} 2 \theta$ at increments of $0.02^{\circ} 2 \theta$. A crystal sample holder was used and the diffractograms were not corrected by background diffraction. Powder diffraction files (PDF) from the International Centre for Diffraction Data (ICDD) were used as references using Jade 6.0 software for observation of aluminum hydroxide.

Aluminum hydroxide and aluminum silicate were also analyzed as reference materials. Aluminum hydroxide was prepared from a $40 \mathrm{mg} \cdot \mathrm{dm}^{-3}$ aluminum solution at $\mathrm{pH}$ 9. Aluminum silicate was purchased from Kanto Chemicals Inc.

\subsection{Fourier Transform Infrared Spectroscopy (FT-IR) Analysis}

The freeze dried residues analyzed by XRD analysis were also used for FT-IR (JASCO, Inc. FT-IR4200, Tokyo, Japan) analysis. Infrared absorption spectra were recorded on an IR spectrometer using the pressed $\mathrm{KBr}$ pellet technique. Approximately $0.6 \mathrm{mg}$ sample and $200 \mathrm{mg} \mathrm{KBr}$ were mixed in an agate mortar, and pressed in a $10 \mathrm{~mm} \varphi$ pellet die under a vacuum. The equipment was operated under prescribed conditions with a scanning speed and resolution of $2 \mathrm{~mm} \cdot \mathrm{s}^{-1}$ and $4 \cdot \mathrm{cm}^{-1}$, respectively [12].

Aluminum hydroxide and aluminum silicate were also analyzed as reference materials, which were prepared as for XRD analysis.

\section{Results and Discussion}

\subsection{Removal Characteristics}

Silicate removal characteristics to aluminum dosage are shown in Figure 1. In these experiments, the $\mathrm{pH}$ was 9 and the initial concentration of silicate was 0.71 or $1.78 \mathrm{mmol} \cdot \mathrm{dm}^{-3}\left(20 \mathrm{or} 50 \mathrm{mg} \cdot \mathrm{dm}^{-3}\right.$ $\mathrm{Si})$, approximately the same silicate concentration as the wastewater from the incinerator.

Figure 1. Silicate removal by co-precipitation and adsorption. Solid or dashed lines are calculated values considering the chemical equilibrium of kaolinite formation. The initial silicate concentration was either 0.71 or $1.78 \mathrm{mmol} \cdot \mathrm{dm}^{-3}$.

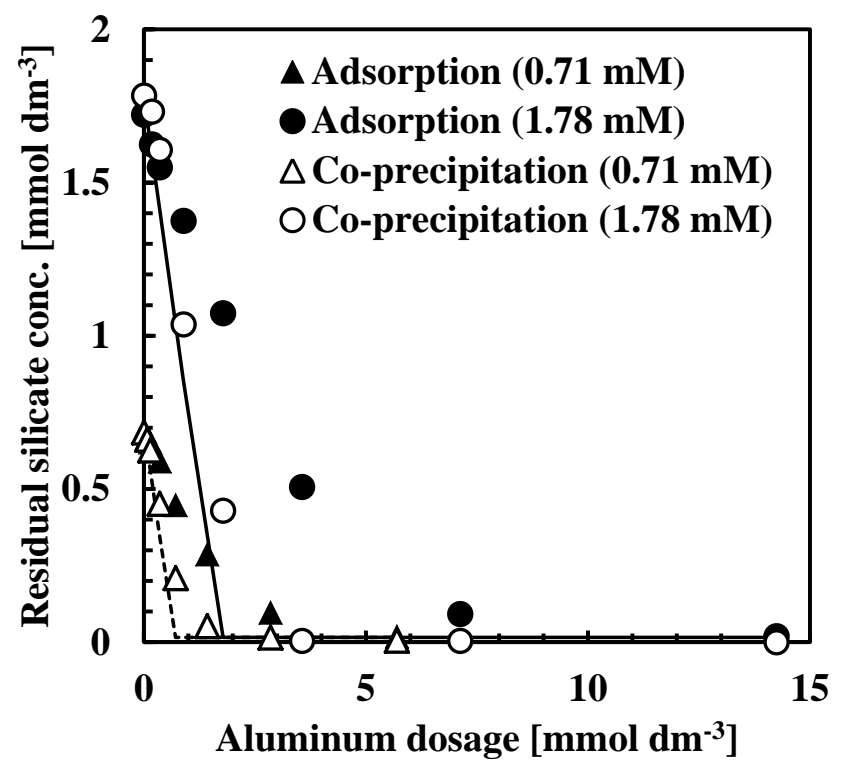


The co-precipitation and adsorption experimental results shown in Figure 1 indicated that more silicate was removed using co-precipitation. Solid or dashed lines in Figure 1 show the calculated residual silicate concentration from the thermodynamic solubility constant, $K$, of kaolinite $\left[\mathrm{Al}_{2} \mathrm{Si}_{2} \mathrm{O}_{5}(\mathrm{OH})_{4}\right]$ :

$$
\mathrm{Al}_{2} \mathrm{Si}_{2} \mathrm{O}_{5}(\mathrm{OH})_{4}+6 \mathrm{H}^{+} \leftrightarrow \mathrm{H}_{2} \mathrm{O}+2 \mathrm{H}_{4} \mathrm{SiO}_{4}+2 \mathrm{Al}^{3+} \log K=7.435
$$

in this calculation, boehmite precipitation was also included because precipitates were characterized as a combination of boehmite and poorly crystalline kaolinite:

$$
\mathrm{AlOOH}+3 \mathrm{H}^{+} \leftrightarrow \mathrm{Al}^{3+}+2 \mathrm{H}_{2} \mathrm{O} \quad \log K=8.578
$$

the theoretical residual silicate concentration corresponded to the co-precipitation experiments. This observation suggests that the mechanism of silicate uptake in the co-precipitation process was because of kaolinite formation. However, in some plots of $0.71-1.8 \mathrm{mmol} \cdot \mathrm{dm}^{-3}$ aluminum dosage, corresponding to an initial $\mathrm{Si} / \mathrm{Al}$ molar ratio of $1-2$, the theoretical residual silicate was less than the experimental co-precipitation. Under these conditions, kaolinite formation would not have achieved equilibrium within the $1 \mathrm{~h}$ reaction time.

\subsection{Sorption Isotherm}

Figure 2 shows the sorption isotherm obtained from co-precipitation and adsorption experiments at $\mathrm{pH} 9$ after $1 \mathrm{~h}$. In these experiments, the initial silicate concentration was fixed at 0.71 or $1.78 \mathrm{mmol} \cdot \mathrm{dm}^{-3}\left(20\right.$ or $\left.50 \mathrm{mg} \cdot \mathrm{dm}^{-3} \mathrm{Si}\right)$ while the $\mathrm{Al}(\mathrm{III})$ concentrations ranged from $0.07-14.24 \mathrm{mmol} \cdot \mathrm{dm}^{-3}\left(2-384 \mathrm{mg} \cdot \mathrm{dm}^{-3} \mathrm{Al}\right)$ to obtain an initial $\mathrm{Si} / \mathrm{Al}$ molar ratio of $0.125,0.25,0.5,1$, 2, 5 or 10. Figure 2 shows the initial Si/Al molar ratio only for plots in which the initial Si/Al molar ratio was above 1 . In these experiments, sorption density was greater at low aluminum dosages.

Figure 2. Sorption isotherm obtained from co-precipitation and adsorption experiments at $\mathrm{pH}$ 9. The initial silicate concentration was either 0.71 or $1.78 \mathrm{mmol} \cdot \mathrm{dm}^{-3}$.

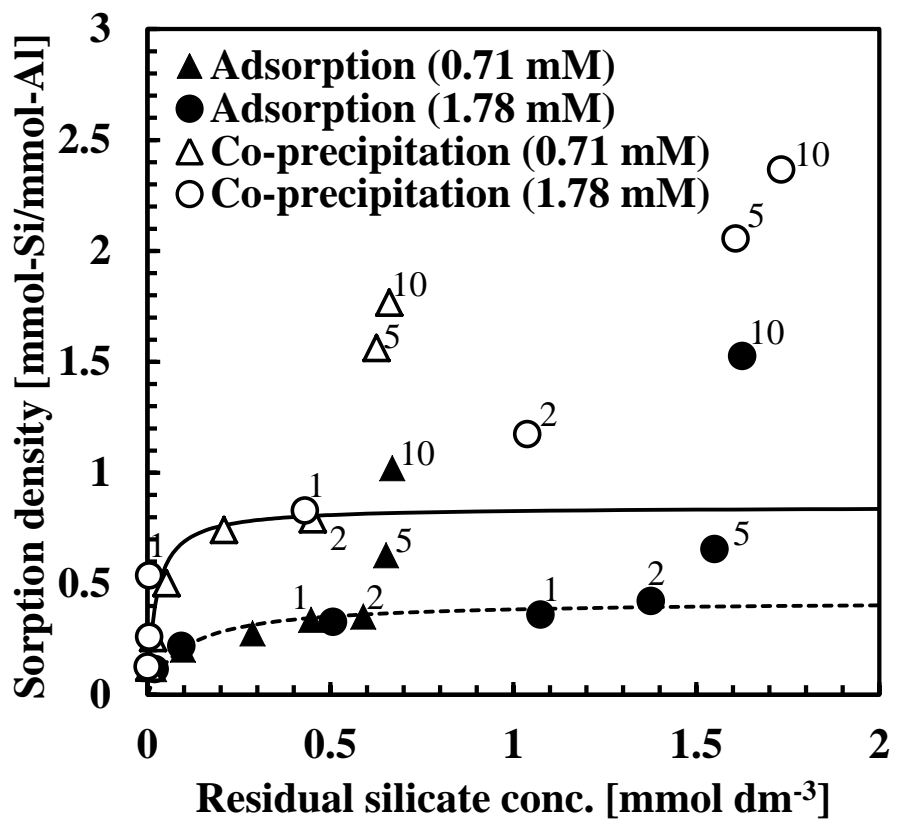


Figure 2 indicates that the silicate sorption density for co-precipitation was greater than the adsorption process. In all experiments, sorption isotherms indicated Brunauer-Emmett-Teller (BET) type isotherms, indicating that silicate removal mechanisms in both co-precipitation and adsorption processes involved more than a simple adsorption [7-11]. Silicate sorption density increased substantially when the initial Si/Al molar ratio was $>2$ in the all experiments, indicating that the mechanism of silicate uptake was three dimensional. This three dimensional uptake may involve adsorption of polymerized silicate in addition to kaolinite precipitation because sorption density exceeded $1 \mathrm{mmol}-\mathrm{Si} / \mathrm{mmol}-\mathrm{Al}$. We have confirmed previously that multiple complexes such as $\mathrm{AlF}_{3}{ }^{0}$ and $\mathrm{AlF}_{4}^{-}$adsorb to aluminum hydroxide, and showed that fluorine sorption density exceeded $1 \mathrm{mmol}-\mathrm{F} / \mathrm{mmol}-\mathrm{Al}$ when the initial F/Al molar ratio was $>3$ in both co-precipitation and adsorption processes [11].

From Langmuir plots using data of the initial $\mathrm{Si} / \mathrm{Al}$ molar ratio not greater than two, a linear relationship was obtained and the saturated sorption density was calculated as $0.85 \mathrm{mmol}-\mathrm{Si} / \mathrm{mmol}-\mathrm{Al}$ for the co-precipitation process (solid line in Figure 2) and $0.42 \mathrm{mmol}-\mathrm{Si} / \mathrm{mmol}-\mathrm{Al}$ for the adsorption process (dashed line in Figure 2). The saturated sorption density in co-precipitation was 2-fold greater than observed in the adsorption experiments. In co-precipitation experiments, more silicate could adsorb to aluminum hydroxide because as fresh particles of aluminum hydroxide precipitated, its surface maintained a high capacity for silicate sorption. Additionally, more kaolinite could precipitate during the co-precipitation process because of the aluminum ions present in the solution and kaolinite precipitation did not go through dissolution of aluminum hydroxide, which is necessary for kaolinite formation in the adsorption process.

\subsection{XRD Analysis}

Figure 3 shows a comparison of XRD spectra of silicate co-precipitated and adsorbed residues as a function of the initial molar ratio of $\mathrm{Si} / \mathrm{Al}$. In these experiments, co-precipitation and adsorption were performed at initial $\mathrm{Si} / \mathrm{Al}$ molar ratios of $0.125,1,2,5$ and 10 at $\mathrm{pH} \mathrm{9,} \mathrm{and} \mathrm{the} \mathrm{initial} \mathrm{aluminum}$ concentration was $1.48 \mathrm{mmol} \cdot \mathrm{dm}^{-3}\left(40 \mathrm{mg} \cdot \mathrm{dm}^{-3} \mathrm{Al}\right)$. The silicate concentration was varied to achieve the target molar ratio. We quantitatively analyzed the $\mathrm{Al}$ and $\mathrm{Si}$ in the precipitates and confirmed that the Si/Al molar ratio in the precipitates corresponded to the sorption density shown in Figure 2.

Generally, it is difficult to investigate the mineralogical forms of silicate phases in wastewater sludge from XRD patterns because they are poorly crystalline. However, we previously found that surface precipitation could be detected from XRD peak shift in As/Fe or As/Al compounds with different molar ratios [7]. Therefore, XRD spectra were investigated for silicate co-precipitated and adsorbed residues in this study.

As shown in Figures 3 and 4, XRD spectra in co-precipitation and adsorption experiments with the same initial Si/Al molar ratio were similar. This suggests that the mechanism of silicate uptake in co-precipitation and adsorption experiments was very similar, whereas their sorption efficiencies differed.

Included in Figures 3 and 4 are the reference XRD spectra of aluminum hydroxide $(\mathrm{Si} / \mathrm{Al}=0)$ and aluminum silicate. The XRD spectrum of aluminum hydroxide had clear broad peaks around $14^{\circ} 2 \theta$, $28^{\circ} 2 \theta, 38^{\circ} 2 \theta, 49^{\circ} 2 \theta$ and $65^{\circ} 2 \theta$, which correspond to poorly crystalline boehmite [13]. Conversely, 
poorly crystalline aluminum silicate had a clear broad peak around $24.9^{\circ} 2 \theta$, corresponding to a XRD spectrum of crystalline kaolinite.

Figure 3. XRD spectra of silicate co-precipitated residues obtained at $\mathrm{pH}$ 9. The initial aluminum concentration was $1.48 \mathrm{mmol} \cdot \mathrm{dm}^{-3}$.

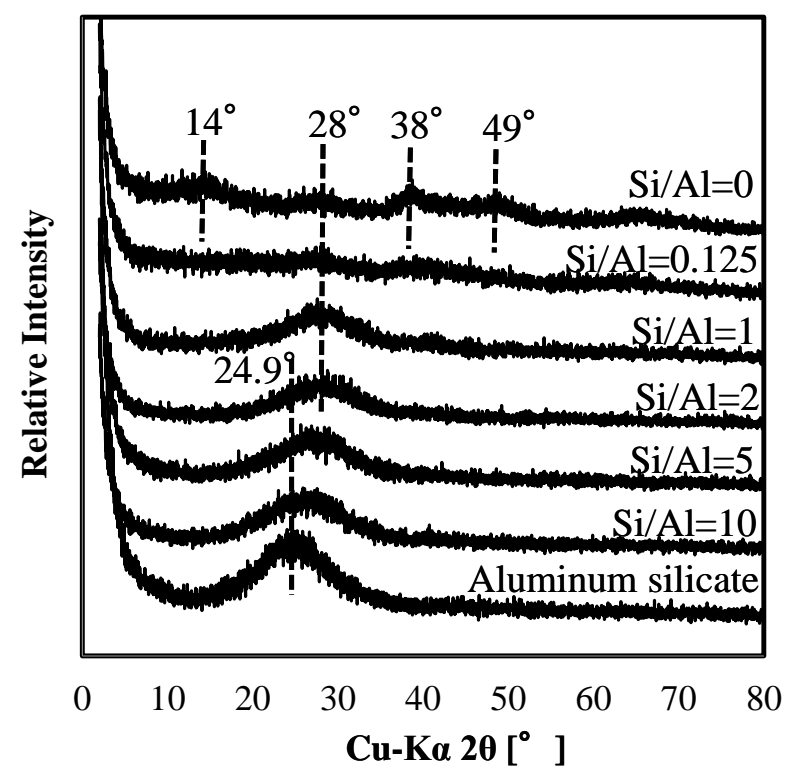

Figure 4. XRD spectra of silicate adsorbed residues obtained at $\mathrm{pH}$ 9. The initial aluminum concentration was $1.48 \mathrm{mmol} \cdot \mathrm{dm}^{-3}$.

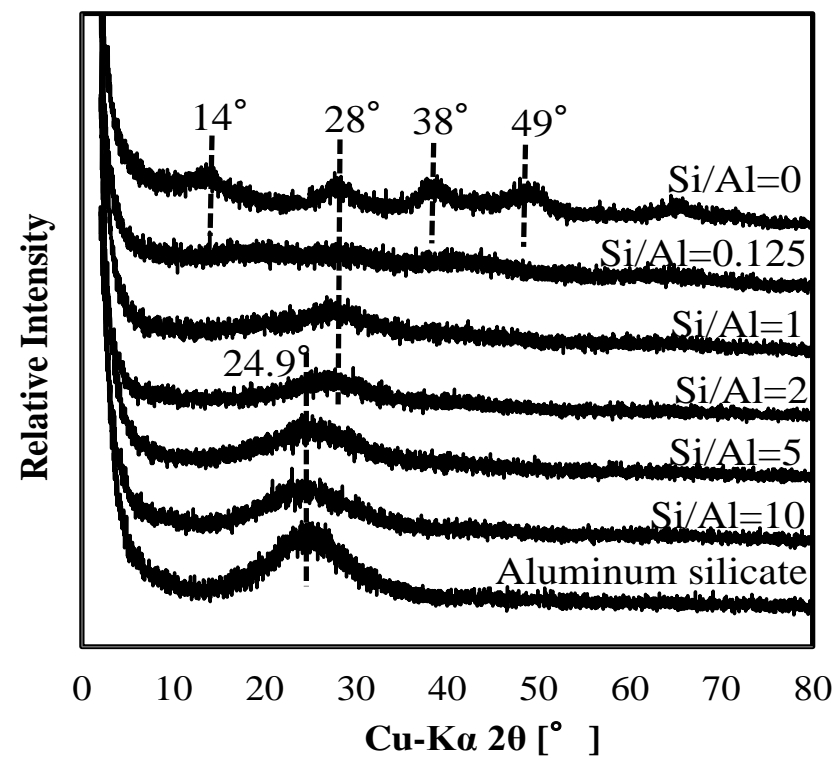

When the initial Si/Al molar ratios were smaller than two, silicate co-precipitated or adsorbed residues had a broad and weak peak at $28^{\circ}$, which corresponds to boehmite. This indicates that the main mechanism of silicate uptake was not kaolinite precipitation, but silicate sorption to aluminum hydroxide at an initial $\mathrm{Si} / \mathrm{Al}$ molar ratio not greater than two in both co-precipitation and adsorption processes. Silicate uptake in both co-precipitation and adsorption processes would make boehmite more amorphous. 
The XRD spectra of residues gradually shifted from $28^{\circ}$ to $24.9^{\circ}$ when the initial Si/Al molar ratio increased from 1 to 10 . Because the XRD peak at $24.9^{\circ}$ originates from poorly crystalline kaolinite, it is considered that precipitation of amorphous kaolinite increases initial Si/Al molar ratios increase. In addition, the XRD spectrum of residue at $\mathrm{Si} / \mathrm{Al}$ ratio of 10 was similar to poorly crystalline aluminum silicate, indicating a mechanism of silicate uptake involving the precipitation of aluminum silicate.

It should be noted that the XRD spectrum peak shift from aluminum hydroxide to aluminum silicate was at $\mathrm{Si} / \mathrm{Al}$ ratio of 2 , and that this was consistent with a steep increase in sorption density (Figure 2). Thus for initial Si/Al molar ratios greater than 2, the removal mechanism of silicate was predominantly precipitation of aluminum silicate, such as poorly crystalline kaolinite, which increased silicate sorption density. However, for the ratios smaller than 2, the main removal mechanism of silicate was adsorption to boehmite.

\subsection{FT-IR Analysis}

Figures 5 and 6 show a comparison of the infrared spectra of silicate co-precipitated and adsorbed residues, as a function of the initial molar ratio of $\mathrm{Si} / \mathrm{Al}$. The infrared spectra of aluminum hydroxide obtained at $\mathrm{pH} 9(\mathrm{Si} / \mathrm{Al}=0)$ and aluminum silicate are shown as reference data. The FT-IR spectrum peaks are assigned in Table 1 [12-17].

Figure 5. FT-IR spectra of silicate co-precipitated residues at $\mathrm{pH} 9$ at an initial aluminum concentration of $1.48 \mathrm{mmol} \cdot \mathrm{dm}^{-3}$.

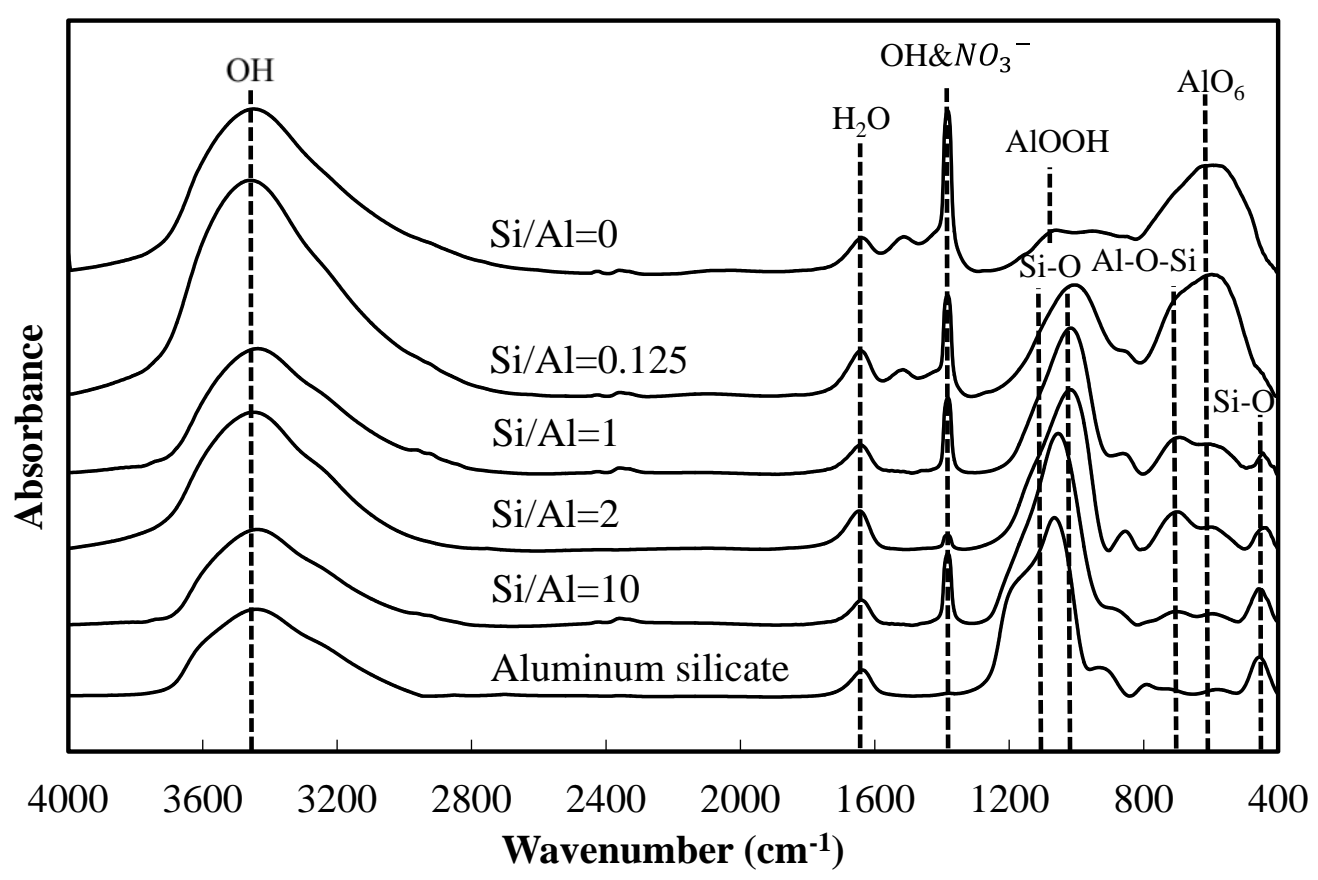

The FT-IR spectra of co-precipitated residues (Figure 5) were almost identical to adsorbed residues (Figure 6). These trends were also observed for XRD analysis (Figures 3 and 4) and indicate a similar mechanism of silicate uptake in co-precipitation and adsorption processes. All the residues showed the $\mathrm{OH}$ stretching band at around $3600 \mathrm{~cm}^{-1}$ and a $\mathrm{H}_{2} \mathrm{O}$ stretching band at $1650 \mathrm{~cm}^{-1}$. In addition, the sharp peak at $1350 \mathrm{~cm}^{-1}$ was attributed to $\mathrm{a} \mathrm{NO}_{3}{ }^{-}$stretching band which remained on the surface. A 
small peak around $1500 \mathrm{~cm}^{-1}$, which was observed at an initial Si/Al molar ratio not greater than 1, originated from $\mathrm{CO}_{2}$ adsorption [18,19]. We confirmed that the particle size of residues decreased with a decrease in the initial Si/Al molar ratio, which suggests that more $\mathrm{CO}_{2}$ would adsorb to residues during Si removal and/or filtration when the initial Si/Al molar ratio was low.

Figure 6. FT-IR spectra of silicate adsorbed residues at $\mathrm{pH} 9$ at an initial aluminum concentration of $1.48 \mathrm{mmol} \cdot \mathrm{dm}^{-3}$.

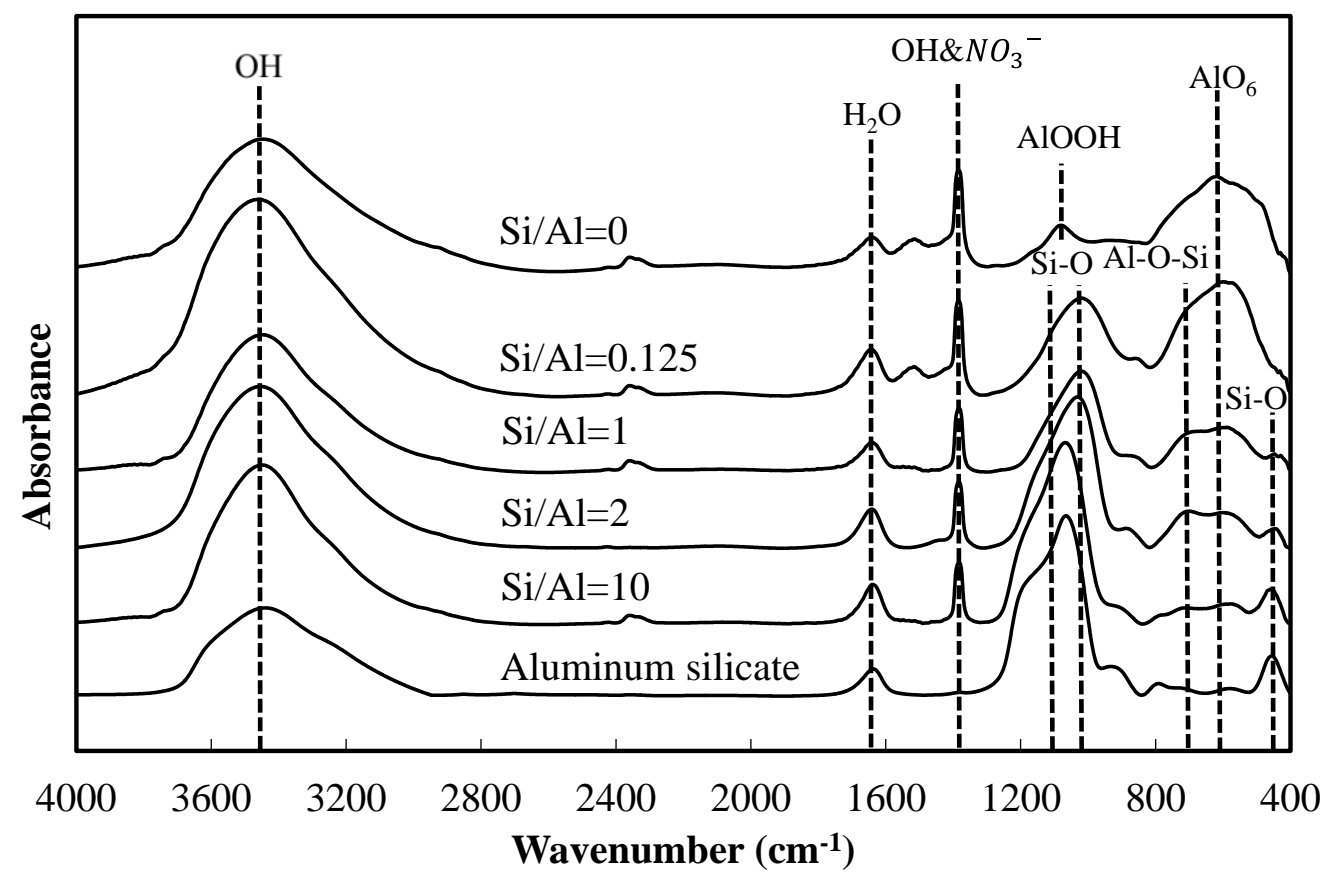

Table 1. Peak assignments in the residue FT-IR spectra.

\begin{tabular}{ccc}
\hline Band location $\left(\mathbf{c m}^{-\mathbf{1}}\right)$ & Band assignments & Band interaction \\
\hline 3650 & $-\mathrm{OH}$ & bend \\
3600 & $-\mathrm{OH}$ & stretch \\
1650 & $\mathrm{H}_{2} \mathrm{O}$ & stretch \\
1350 & $\mathrm{NO}_{3}^{-}, \mathrm{Al}-\mathrm{OH}$ & stretch and bond \\
1105 & $\mathrm{Si}-\mathrm{O}$ & stretch \\
1080 & $\mathrm{AlOOH}$ & stretch \\
1025 & $\mathrm{Si}-\mathrm{O}$ & stretch \\
700 & $\mathrm{Al}-\mathrm{O}-\mathrm{Si}$ & stretch \\
600 & $\mathrm{AlO}$ & stretch and bond \\
432 & $\mathrm{Si}-\mathrm{O}$ & stretch \\
\hline
\end{tabular}

Aluminum hydroxide $(\mathrm{Si} / \mathrm{Al}=0)$ had stretching vibration of $\mathrm{AlOOH}$ at $1080 \mathrm{~cm}^{-1}$ and a bending vibration and stretching vibration of $\mathrm{AlO}_{6}$ at $600 \mathrm{~cm}^{-1}$ [14], which corresponded with boehmite. Therefore, residues obtained at $\mathrm{pH} 9$ without silicate in this study are most likely boehmite.

Typical absorption bands for kaolinite, e.g., $\mathrm{OH}$ vibration bands at around $3650 \mathrm{~cm}^{-1}$, the $\mathrm{Si}-\mathrm{O}-\mathrm{Si}$ absorption bands at $1025 \mathrm{~cm}^{-1}$, the Al-O-Si absorption bands at around $700 \mathrm{~cm}^{-1}$ and the $\mathrm{Si}-\mathrm{O}$ absorption bands at $432 \mathrm{~cm}^{-1}$ were observed for residues at all initial $\mathrm{Si} / \mathrm{Al}$ molar ratios. The intensities of these absorption bands gradually increased as the initial Si/Al molar ratio increased, and gradually 
resembled FT-IR patterns of aluminum silicate. These results suggest that aluminum silicate was poorly crystalline kaolinite and that the mechanism of silicate uptake gradually shifted to precipitation of poorly crystalline kaolinite as the initial $\mathrm{Si} / \mathrm{Al}$ molar ratio was increased.

\subsection{Reaction Rate}

Our results suggest that the mechanism of silicate uptake using aluminum hydroxide was influenced by the initial Si/Al molar ratio. Furthermore, the mechanism of silicate uptake in co-precipitation was almost identical to adsorption, whereas removal efficiency and sorption density was higher in co-precipitation. To determine why removal efficiency was so different between co-precipitation and adsorption, time variations of silicate and aluminum concentrations during silicate removal were compared.

Figures 7 and 8 show residual silicate and aluminum concentrations, respectively, over a 24-h period, at $\mathrm{pH}$ 9. The initial silicate concentration was $1.78 \mathrm{mmol} \cdot \mathrm{dm}^{-3}\left(50 \mathrm{mg} \cdot \mathrm{dm}^{-3} \mathrm{Si}\right)$ and the initial aluminum concentration was 0.71 or $1.78 \mathrm{mmol} \cdot \mathrm{dm}^{-3}$ to achieve a 1 or 2 initial $\mathrm{Si} / \mathrm{Al}$ molar ratio.

Figure 7. Residual silicate concentration in co-precipitation and adsorption experiments at $\mathrm{pH} 9$ over $24 \mathrm{~h}$. The initial silicate concentration was $1.78 \mathrm{mmol} \cdot \mathrm{dm}^{-3}$.

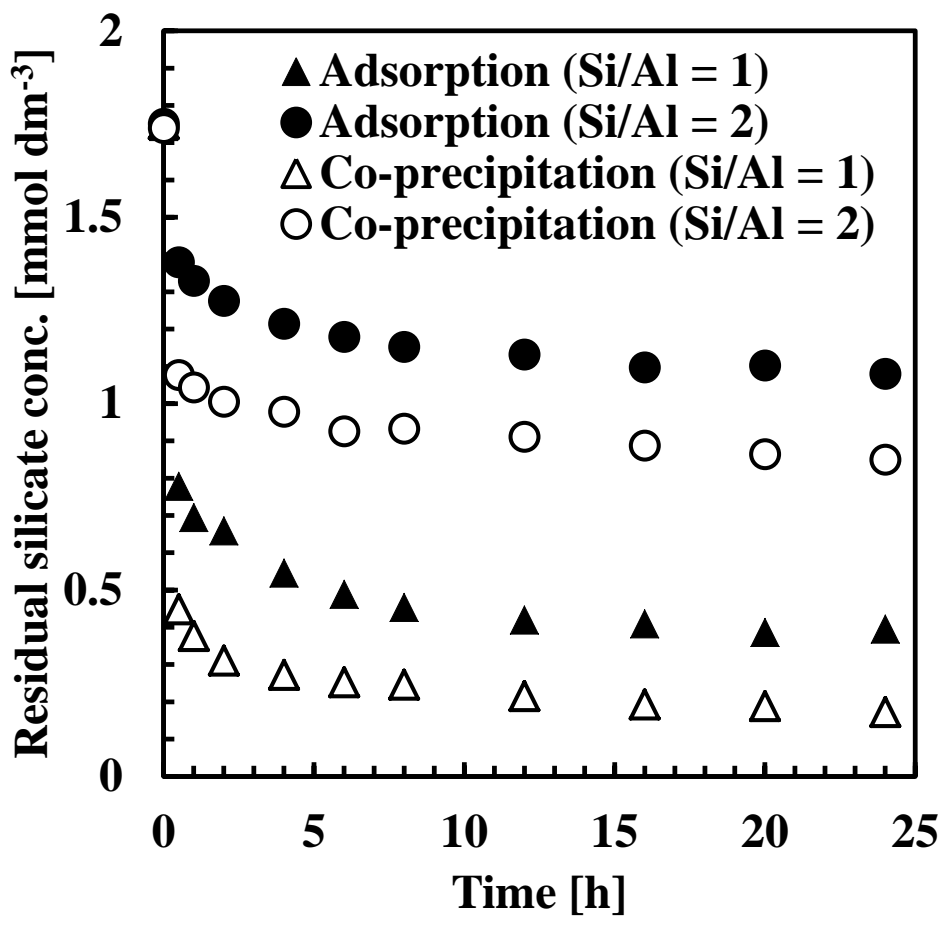

As shown in Figure 7, silicate removal was achieved in two steps: an initial rapid uptake which occurred within a few seconds, followed by a second, slower silicate uptake taking several hours to equilibrate. When comparing co-precipitation and adsorption, the rapid reaction rate in the first step was different, whereas the slow reaction rate in the second step was almost the same.

This first rapid silicate uptake involved the precipitation of boehmite and kaolinite and silicate adsorption to boehmite. In this step, more silicate could be adsorbed to boehmite in co-precipitation because boehmite was freshly precipitated and had a high capacity for adsorption on its surface. In addition, more kaolinite could precipitate during co-precipitation because aluminum existed as ions in the solution, unlike the adsorption process. Aluminum concentration in co-precipitation was slightly 
higher than in the adsorption process (Figure 8). At a thermodynamic equilibrium, aluminum concentration equilibration with boehmite was lower than that equilibrated with kaolinite. Therefore, in the adsorption experiments, dissolution of aluminum in boehmite should be rapid to precipitate kaolinite. Conversely, the second slow step would consist of transformation of boehmite to kaolinite. In this step, because boehmite was already precipitated for co-precipitation and adsorption, dissolution of aluminum ions from boehmite and precipitation of kaolinite engaged a longer reaction time of several hours in both processes.

Figure 8. Residual aluminum concentration in co-precipitation and adsorption experiments at $\mathrm{pH} 9$ over $24 \mathrm{~h}$ : initial silicate concentration was $1.78 \mathrm{mmol} \cdot \mathrm{dm}^{-3}$.

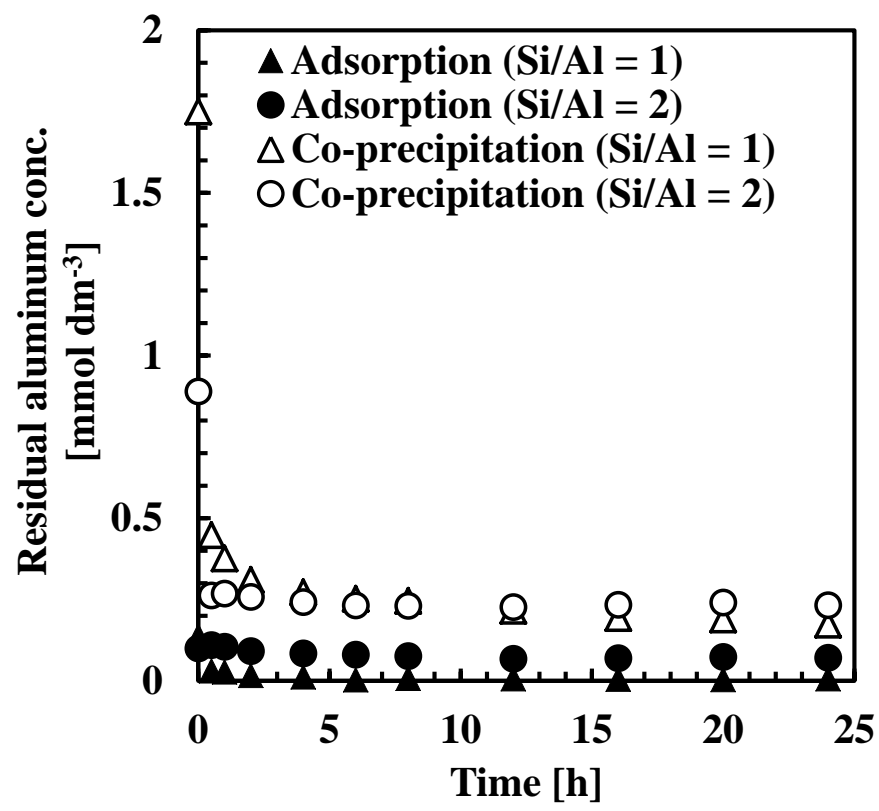

\section{Conclusions}

Removal mechanisms of silicate using aluminum hydroxide in a co-precipitation process were investigated and compared with an adsorption process. In co-precipitation, higher removal efficiency and sorption density were achieved relative to the adsorption process. The isotherms and results of XRD and FT-IR analysis from co-precipitation experiments were almost identical to those observed from adsorption experiments, which suggested that the main mechanism of silicate uptake was similar for the two methods.

A Langmuir type isotherm was obtained both for co-precipitation and adsorption processes for initial Si/Al molar ratios smaller than 2. Conversely, for the ratios larger than 2, a BET type isotherm was obtained. XRD and FT-IR analysis showed that silicate uptake occurred by adsorption to boehmite for initial $\mathrm{Si} / \mathrm{Al}$ molar ratios smaller than 2 , but by precipitation of poorly crystalline kaolinite for ratios larger than 2 , in both co-precipitation and adsorption processes.

Time studies of residual silicate concentrations showed that silicate was removed by two steps: (i) an initial rapid uptake in a few seconds; and (ii) a slow silicate uptake over several hours, in both processes. Only in the first rapid step was the rate of silicate removal higher in co-precipitation relative to the adsorption. The uptake rate in the first step was higher in the co-precipitation process than in 
adsorption process, presumably due to increased silicate adsorption to boemite and rapid precipitation of kaolinite.

The silicate removal mechanism by aluminum hydroxide suggests that continuous addition of aluminum ions, not aluminum hydroxide particles, should result in highly efficient removal of silicate from wastewater.

\section{Acknowledgments}

This research was partially supported by the Ministry of Education, Science, Sports and Culture, Grant-in-Aid for Scientific Research (C), 2012-2014 (24561006, Chiharu Tokoro).

\section{Conflicts of Interest}

The authors declare no conflict of interest.

\section{References}

1. Comb, F.L.; Lee, F. Silica Chemistry and Reverse Osmosis. Ultrapure Water 1996, 13, 41-43.

2. Potts, D.E.; Ahlert, R.C.; Wang, S.S. A critical review of fouling of reverse osmosis membranes. Desalination 1981, 36, 235-264.

3. Sahachaiyunta, P.; Koo, T.; Sheikholeslami, R. Effect of several inorganic species on silica fouling in RO membranes. Desalination 2002, 144, 373-378.

4. Sheikholeslami, P.; Al-Mutaz, I.S.; Koo, T.; Young, A. Pretreatment and the effect of cations and anions on prevention of silica fouling. Desalination 2001, 139, 83-95.

5. Sheikholeslami, R.; Bright, J. Silica and metals removal by pretreatment to prevent fouling of reverse osmosis membranes. Desalination 2002, 143, 255-267.

6. Sugita, H.; Bamdo, Y.; Nakamura, M. Effects of $\mathrm{pH}$ and operational conditions on silica removal from geothermal brine by seeding method using silica gel. Kagaku Kogaku Ronbunshu 1998, 24, 552-557 (in Japanese).

7. Tokoro, C.; Yatsugi, Y.; Koga, H.; Owada, S. Sorption mechanisms of arsenate during co-precipitation with ferrihydrite in aqueous solution. Environ. Sci. Technol. 2010, 44, 638-643.

8. Tokoro, C.; Haraguchi, D.; Owada, S. Sorption mechanisms of arsenic coprecipitation with ferric or aluminum hydroxides in aqueous solution. Res. Adv. Environ. Sci. Technol. 2010, 1, 1-14.

9. Haraguchi, D.; Tokoro, C.; Oda, Y.; Owada, S. Sorption mechanisms of arsenate in aqueous solution during coprecipitation with aluminum hydroxide. J. Chem. Eng. Jpn. 2012, 46, 173-180.

10. Haraguchi, D.; Oda, Y.; Tokoro, C.; Owada, S. Comparison between aluminum hydroxide coprecipitation and adsorption for removal of dilute $\mathrm{As}(\mathrm{V})$ from wastewater. J. MMIJ 2010, 127, 82-87.

11. Haraguchi, D.; Tokoro, C.; Owada, S. Comparison between aluminum hydroxide coprecipitation and adsorption for removal of fluoride from wastewater. J. MMIJ 2010, 127, 26-31.

12. Miyawaki, R.; Tomura, S.; Inukai, K.; Shibasaki, Y.; Okazaki, M.; Samejima, S.; Satokawa, S. Formation process of kaolinite from the amorphous mixture of silica and alumina. Clay Sci. 1992, 8, 273-284. 
13. Wang, S.G.; Ma, Y.; Shi, Y.J.; Gong, W.X. Defluoridation performance and mechanism of nano-scale aluminum oxide hydroxide in aqueous solution. J. Chem. Technol. Biotechnol. 2009, 84, 1043-1050.

14. Yokoyama, T.; Nishu, K.; Torii, S.; Ikeda, Y. Mullite precursor Part I. Characterization of mullite precursor formed by a reaction of monosilicic acid on aluminum hydroxide. J. Mater. Res. 1997, 12, 2111-2116.

15. Vimont, A.; Lavalley, J.C.; Francke, L.; Demourgues, A.; Tressaud, A.; Daturi, M. Infrared study of the surface properties of HTB-type Al-, Cr-, Fe-hydroxyfluorides. J. Phys. Chem. B 2004, 108, 3246-3255.

16. Cross, A.D.; Natori, S.; Chihara, G. An Introduction to Practical Infrared Spectroscopy, 3rd ed.; Tokyo kagaku doujin: Tokyo, Japan, 1983; pp. 89-119.

17. Favaro, L.; Boumaza, A.; Roy, P.; Lédion, J.; Sattonnay, G.; Brubach, J.B.; Huntz, A.M.; Tétot, R. Experimental and ab initio infrared study of $\chi$-, $\kappa$ - and $\alpha$-aluminas formed from gibbsite. J. Solid State Chem. 2010, 183, 901-908.

18. Arato, T.; Tochigi, K.; Tamamura, T. Characterization for $\alpha-\mathrm{Al}_{2} \mathrm{O}_{3}$ and some hydrated aluminas by fourier transform infrared photoacoustic spectroscopy. J. Ceram. Soc. Jpn. 1990, 98, 726-731.

19. AXE, K.; Persson, P. Time-dependent surface speciation of oxalate at the water-boehmite $(\gamma-\mathrm{AlOOH})$ interface: Implications for dissolution. Geochim. Cosmochim. Acta 2001, 65, 4481-4492.

(C) 2014 by the authors; licensee MDPI, Basel, Switzerland. This article is an open access article distributed under the terms and conditions of the Creative Commons Attribution license (http://creativecommons.org/licenses/by/3.0/). 